\title{
Socio-Demographic Factors Associated with Medication Adherence Among People Living with HIV in Kumasi Metropolis, Ghana.
}

Collins Adu ( $\square$ collinsadu80@yahoo.com )

Kwame Nkrumah University of Science and Technology

Kofi Akohene Mensah

Kwame Nkrumah University of Science and Technology

Bright Opoku Ahinkorah

University of Technology Sydney

Abdul-Aziz Seidu

University of Cape Coast

Anita Yeboah Minta

Kwame Nkrumah University of Science and Technology

Andrews William Tetteh

Kwame Nkrumah University of Science and Technology

\section{Research Article}

Keywords: Antiretroviral therapy, HIV/AIDS, Medication adherence, People living with HIV, Public health

Posted Date: June 3rd, 2021

DOl: https://doi.org/10.21203/rs.3.rs-549467/v1

License: (9) (i) This work is licensed under a Creative Commons Attribution 4.0 International License.

Read Full License 


\section{SOCIO-DEMOGRAPHIC FACTORS ASSOCIATED WITH MEDICATION}

2 ADHERENCE AMONG PEOPLE LIVING WITH HIV IN KUMASI METROPOLIS,

3 GHANA.

4 Collins $\mathrm{Adu}^{1 *}$, Kofi Akohene Mensah ${ }^{2}$, Bright Opoku Ahinkorah ${ }^{3}$, Abdul-Aziz Seidu ${ }^{4,5}$, Anita

$5 \quad$ Yeboah Minta ${ }^{6}$, Andrews William Tetteh ${ }^{1}$

$6 \quad{ }^{1}$ Department of Health Promotion, Education and Disability Studies, Kwame Nkrumah University

7 of Science and Technology, Kumasi, Ghana

$8 \quad{ }^{2}$ Department of Health Policy, Management and Economic, Kwame Nkrumah University of

9 Science and Technology, Kumasi, Ghana

$10{ }^{3}$ School of Public Health, Faculty of Health, University of Technology Sydney, Australia

$11{ }^{4}$ Department of Population and Health, University of Cape Coast, Cape Coast, Ghana

$12 \quad{ }^{5}$ College of Public Health, Medical and Veterinary Services, James Cook University, Australia

$13{ }^{6}$ Department of Population, Family and Reproductive health, Kwame Nkrumah University of

14 Science and Technology, Kumasi, Ghana

$15 *$ Corresponding Author

16 Email addresses:

17 *CA: collinsadu80@yahoo.com

18 KAM: akohenemensah@yahoo.com

19 BOA: brightahinkorah@gmail.com

20 AS: abdul-aziz.seidu@stu.ucc.edu.gh

21 AYM: minilovek4.am@gmail.com

22 AWT: ebotetteh@gmail.com 


\section{Abstract}

\section{Background}

25 Medication adherence plays a great role in the survival of people living with HIV globally. In

26 Ghana, there is a considerable decline in the prevalence rate of HIV/AIDS, however, the number

27 of people on antiretroviral therapy keeps adding up. We assessed the socio-demographic factors

28 associated with medication adherence among people living with HIV in Kumasi Metropolis, 29 Ghana.

\section{Method}

32 A quantitative study using descriptive, and analytical cross-sectional study design was carried out 33 among 420 people living with HIV (PLHIV) accessing healthcare at Kumasi South Regional

34 Hospital. A structured questionnaire was used to gather information on medication adherence and 35 socio-demographic factors influencing medication adherence. Analyses of the data were done 36 using Excel version 2013 and Stata version 14.2. The descriptive data were presented using

37 frequencies and percentages. Univariate and multivariate analyses were performed to establish the 38 association between socio-demographic factors and adherence to medication among people living 39 with HIV. Statistical significance for all testing was set as $\mathrm{p}<0.05$.

\section{Results}

41 About 69 out of 100 PLHIV accessing healthcare at Kumasi South Regional Hospital adhered to

42 their medication. Socio-demographic factors such as age and monthly disposable income were 43 established to be influencing medication adherence among PLHIV. For instance, PLHIV aged 44 more than $41(\mathrm{aOR}=12.67 ; \mathrm{CI}=1.36-118.11)$ were more likely to adhere to medication as 
45 compared to those aged 18-23. Also, PLHIV who earned less than GHC500 $(\mathrm{aOR}=2.18 ; \mathrm{CI}=1.05-$

46 4.50) were more likely to adhere to medication as compared to those who earned more than

$47 \mathrm{GHC1} 1,000$.

\section{Conclusion}

49 Majority of PLHIV adhered to their medication. Therefore, policy makers such as Ghana AIDS

50 Commission, Ministry of Health, Ghana Health Service, and National AIDS Control Programme

51 should consider factors such as socio-demographic factors when designing and implementing

52 programmes on medication adherence among PLHIV.

53 Keywords: Antiretroviral therapy, HIV/AIDS, Medication adherence, People living with HIV,

54 Public health

55

56

57

58

59

60

61

62

63 


\section{Background}

65 Medication adherence plays a great role in the survival of people living with HIV (PLHIV) 66 globally as HIV/AIDS continues to be an issue of public health importance. HIV/AIDS was

67 discovered in 1981 which has claimed a lot of lives to date ${ }^{1}$. In 2013 , it was estimated that HIV 68 affected about 78 million people with about 39 million dying of the disease since it was discovered ${ }^{2}$ 69 . It was also estimated that about $71 \%$ of the 34.7 million PLHIV globally reside in sub-Saharan 70 Africa $^{3}$. 1.8 million people were newly diagnosed in 2017 out of the 36.9 million PLHIV ${ }^{1,4}$ with 71 about 53\% in sub-Saharan Africa. There is a higher prevalence rate of HIV within the sub-Saharan

72 Africa region than the global average of $0.8 \%^{5}$. In Ghana, ever since HIV was identified in $1986^{3}$ 73 , there has been a considerable decline in the prevalence rate, however, the number of people on 74 antiretroviral therapy (ART) keeps adding up ${ }^{6}$. Sixty-two percent out of 270,000 PLHIV are 75 females and thirty-eight percent are males in Ghana ${ }^{3}$. According to the 2014 Ghana Demographic 76 and Health Survey, HIV prevalence in Ghana was $2.0 \%$, having decreased marginally from $2.2 \%$ 77 in $2006^{7}$.

78 Since, medication adherence has been the focus of many researchers, HIV/AIDS is becoming a 79 manageable chronic condition. The National AIDS Control Programme (NACP) of Ghana has 80 introduced maximization of adherence to medication among some of the strategies in the fight 81 against the disease ${ }^{8}$. The definition of the word 'adherence' is very complex which includes 82 adherence to nutritional requirements, scheduled visits (time), and dosage (medication) ${ }^{9}$. 83 Medication adherence is defined as taking all medication at the appropriate time with the 84 appropriate dosage as prescribed by a healthcare provider ${ }^{10,11}$. The arrival of ART has improved 85 rates of mortality and morbidity internationally ${ }^{12}$. ART is introduced immediately after a person 86 is infected with the disease ${ }^{13}$. Evidence has shown that ART contributes to the delay of the 
87 progression of HIV infection to AIDS which eventually slows the spread of the disease across

88 communities $^{14,15}$. Medication adherence is paramount for effective management of HIV when it

89 is at $100 \%{ }^{16}$. A study by Bezabhe et al. ${ }^{17}$ showed that PLHIV on ART should be instructed to

90 attain $\geq 95 \%$ adherence to medication. In addition to the maximal viral suppression when

91 medication adherence is $\geq 95 \%^{18,19}$, there is a reduction in the rate of opportunistic infections ${ }^{20}$.

92 Non- adherence to medication is associated with the development of HIV drug resistance strains,

93 recurrent hospitalization and eventually death ${ }^{13,20,21,22,23}$

94 Although several studies have been conducted in Asia ${ }^{24}$, sub-Saharan Africa ${ }^{24,25}$ and in specific

95 countries, China ${ }^{26}$ and Botswana ${ }^{27}$ with regards to medication adherence among PLHIV, results

96 indicate that, there have been variations in medication adherence. This suggests that there are

97 various national and regional disparities as far as adherence is concerned. Therefore, findings of

98 those studies conducted may not be applicable in the context of Ashanti region, Ghana. Previous

99 studies on adherence to medication in Ghana accounted adherence to medication rate at $67 \%$ in $1002015^{3}, 73 \%$ in $2018^{28}, 62.2 \%$ in $2013^{29}, 51.4 \%$ in $2014^{30}$ and $75 \%$ in $2017^{31}$. These studies were

101 conducted in Western region, Central region, Upper West region, Volta region and Eastern region

102 of Ghana respectively. However, these rates hide many geographical disparities due to cultural

103 specificities which may differ across geographical zones of the country. Evidence from the

104 previous studies reviewed indicates that none of such studies has been conducted in Kumasi

105 Metropolis in the Ashanti Region, the most populated region in Ghana. It is against this

106 background that this study sought to assess the socio-demographic factors associated with

107 medication adherence among PLHIV accessing healthcare at Kumasi South Regional Hospital.

108 The outcome of the study will serve as a lesson for the hospital, the Region, and the Country as a 109 whole. 
Methods

\section{Study design and setting}

113 This study employed a quantitative study using analytical and descriptive cross-sectional study 114 design. With a cross-sectional study design, the researcher measures the outcome and the exposure 115 in the study participants at the same time ${ }^{32}$. Data was collected from the month of October to 116 December, 2020. A structured questionnaire was used to collect data. Questionnaires were

117 administered by trained health workers to collect information on medication adherence and socio118 demographic factors influencing adherence to medication among PLHIV. The questions on 119 medication adherence were asked in the local dialect (Twi) which was then translated into English. 120 Prior to the commencement of the study, about twenty (20) questionnaires were piloted at Suntreso 121 Government Hospital to determine the validity and reliability of the data collection tool.

122 This study was conducted at Kumasi South Hospital, the regional hospital in the Ashanti Region 123 of Ghana. This regional hospital is one of the hospitals in the region that provides antiretroviral 124 therapy to PLHIV in Ghana. The hospital is at the center of the region, it is raised 250 and 300 125 meters above sea level and it is settled between longitude $1.30^{0}$ West and latitude $6.35^{0}$ North and $126 \quad 6.40^{0}$ South $^{7}$. Kumasi South Regional Hospital was constructed in 1976, as an urban health center 127 and was later changed to be the Kumasi South Regional Hospital. In 2002, the hospital was uprated 128 to the status of a regional hospital. The regional hospital, a national health insurance scheme 129 accredited facility has 140-bed capacity. Kumasi South Regional Hospital is located in Chirapatre, 130 within the Kumasi Metropolis. About 30.3\% of the population in Kumasi Metropolis is in Asokwa 131 where Kumasi South Hospital is located ${ }^{7}$. 
132 Kumasi South Hospital is surrounded by seventeen health facilities, among these facilities; CHAG 133 and government own one facility each and the remaining are privately owned. In 2017, HIV/AIDS134 related condition was recorded among top ten OPD morbidities. The hospital provides STI, VCT, 135 and ART services for PLHIV.

137 Population and sampling

138 The study population was PLHIV accessing healthcare at Kumasi South Hospital, Ghana. The total 139 population of PLHIV accessing healthcare at Kumasi South Hospital as at the time of the study 140 was 4,235. A sample size of 420 PLHIV on ART completed the survey that gave a response rate 141 of $100 \%$ (420/420). A simple random sampling method using the lottery method was employed to 142 sample the respondents. With the lottery method, numbers 0 and 1 were written on each sheet of 143 paper totaling 840 , and folded into a polythene bag. Based on the average daily attendance at the 144 clinic, eligible participants were allowed to randomly pick one of the folded papers in the polythene 145 bag during the period of data collection. Eligible participants who picked a sheet of paper with 1 146 written on the sheet were selected to take part in the study. This act was repeated continuously 147 until the required sample size was attained.

\section{Definition of variables}

Outcome variable

150 The outcome variable for the study was medication adherence among PLHIV. This variable was 151 derived from asking respondents “Did [NAME] adhere to medication?". Responses to this question 152 were 'Yes' and 'No'. The response was coded as 'No' $=0$ and 'Yes' $=1$. 


\section{Independent variables}

155 The study included nine (9) independent variables in our estimations. The variables were age, 156 gender, marital status, ethnicity, employment status, level of education, place of residence, 157 religious affiliation, and disposable monthly income. None of these variables was selected a priori, 158 instead, the selection was based on conclusions drawn from previous studies on medication 159 adherence as well as their theoretical and conceptual bearings on HIV/AIDS ${ }^{26,28}$.

\section{Statistical analyses}

162 We employed both descriptive and inferential analytical approaches. Questionnaires were checked 163 for completeness and internal errors during data collection. Questionnaires were numbered, sorted, 164 and kept in files. Analyses of the data were done using Excel version 2013 and Stata version 14.2. 165 The descriptive data were presented using frequencies and percentages where necessary. 166 Univariate and multivariate analyses were performed to establish any socio-demographic factors 167 of PLHIV influencing medication adherence. Statistical significance for all testing was set as $168 \mathrm{p}<0.05$. The analysis was done in three steps. Firstly, medication adherence among PLHIV in

169 Ghana was graphically computed. The second step was the computation of the socio-demographic 170 information of PLHIV in Ghana. Next, a binary logistic regression analysis was carried out to 171 assess the level of medication adherence (dependent variable) among PLHIV in Ghana and socio172 demographic factors (independent variables) of PLHIV (see Table 2). Socio-demographic factors 173 of PLHIV that showed statistical significance in the univariate regression analysis were further 174 analysed using multivariate logistic regression. 


\section{Results}

176 Figure 1 shows the medication adherence among PLHIV in Ghana. The level of medication

177 adherence among PLHIV accessing healthcare at Kumasi South Hospital in Ghana was 69.05\%.

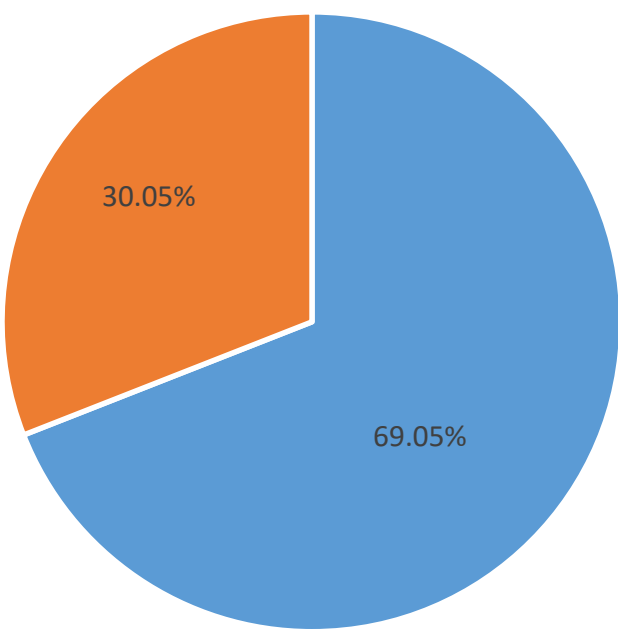

- Yes $\because$ No

Figure 1: Medication adherence among PLHIV

180

\section{Socio-demographic information of PLHIV in Kumasi Metropolis, Ghana}

182 Table 1 displays the socio-demographic information of PLHIV. Majority of PLHIV (79.76\%)

183 were females while the remaining (20.24\%) were males. Also, most of the PLHIV (64.05\%) were 184 above the age of 41 with a mean age of 45 years ranging from 18 to 80 years. A higher proportion 185 of PLHIV with JHS/Middle education (62.38\%) adhered to medication. Furthermore, the Akan 186 (72.62\%), PLHIV residing in urban centers (67.62\%), Christians $(86.19 \%)$, those who were 
187 working (81.19\%), and those who had less than GHC500 as their disposable income at the end of 188 the month $(75.24 \%)$ had the highest proportion of medication adherence.

189 Table 1. Socio-demographic information of PLHIV

\begin{tabular}{|c|c|c|c|}
\hline Variable & Categories & Frequency $(n=420)$ & Percent (\%) \\
\hline \multirow[t]{5}{*}{ Age } & $18-23$ & 6 & $1.43 \%$ \\
\hline & $24-29$ & 31 & $7.38 \%$ \\
\hline & $30-35$ & 51 & $12.14 \%$ \\
\hline & $36-41$ & 63 & $15.00 \%$ \\
\hline & Above 41 & 269 & $64.05 \%$ \\
\hline \multirow[t]{2}{*}{ Gender } & Male & 85 & $20.24 \%$ \\
\hline & Female & 335 & $79.76 \%$ \\
\hline \multirow[t]{4}{*}{ Marital Status } & Married & 177 & $42.14 \%$ \\
\hline & Single & 115 & $27.38 \%$ \\
\hline & Divorced & 54 & $12.86 \%$ \\
\hline & Widowed & 74 & $17.62 \%$ \\
\hline \multirow[t]{4}{*}{ Ethnicity } & Akan & 305 & $72.62 \%$ \\
\hline & Ewe & 23 & $5.48 \%$ \\
\hline & $\mathrm{Ga}$ & 7 & $1.67 \%$ \\
\hline & North & 85 & $20.24 \%$ \\
\hline \multirow[t]{2}{*}{ Employment status } & Yes & 341 & $81.19 \%$ \\
\hline & No & 79 & $18.81 \%$ \\
\hline \multirow[t]{4}{*}{ Level of education } & None & 85 & $20.24 \%$ \\
\hline & Primary & 45 & $10.71 \%$ \\
\hline & JHS/Middle & 262 & 62.38 \\
\hline & Tertiary & 28 & $6.67 \%$ \\
\hline \multirow[t]{2}{*}{ Place of residence } & Urban & 284 & $67.62 \%$ \\
\hline & Rural & 136 & $32.38 \%$ \\
\hline
\end{tabular}




\begin{tabular}{llll}
\hline Religious Affiliation & Christianity & 362 & $86.19 \%$ \\
& Islamic & 47 & $11.19 \%$ \\
& Traditional & 11 & $2.62 \%$ \\
Disposable income & $<500$ & 316 & $75.24 \%$ \\
& $500-1000$ & 62 & $14.76 \%$ \\
& $>1000$ & 42 & $10.00 \%$ \\
\hline
\end{tabular}

192 Socio-demographic factors associated with medication adherence among PLHIV in Kumasi

193 Metropolis, Ghana

195 Table 2 presents the socio-demographic factors associated with medication adherence among 196 PLHIV in Ghana. With the univariate and multivariate regression analysis, the results showed that 197 socio-demographic factors such as age and disposable monthly income were identified to be 198 influencing medication adherence among PLHIV as detailed in Table 2. For instance, respondents 199 who received less than GHC500 $(\mathrm{aOR}=2.16 ; \mathrm{CI}=1.05-4.50)$ were more likely to adhere to their 200 medication compared with those who received more than GHC1,000 as their monthly disposable 201 income. Also, PLHIV aged above 41 years $(\mathrm{aOR}=12.67 ; \mathrm{CI}=1.36-118.11)$ were more likely 202 were to adhere to their medication compared to those between the ages of $18-23$.

Table 2 Socio-demographic factors associated with medication adherence among PLHIV

\begin{tabular}{cllcccc}
\hline Variables & $\begin{array}{c}\text { Crude } \\
\text { Odds Ratio }\end{array}$ & $\begin{array}{l}\mathbf{9 5 \%} \\
\text { Confidence } \\
\text { Interval }\end{array}$ & $\begin{array}{c}\text { p- } \\
\text { value }\end{array}$ & $\begin{array}{c}\text { Adjusted } \\
\text { Odds } \\
\text { Ratio }\end{array}$ & $\begin{array}{c}\mathbf{9 5 \%} \\
\text { Confidence } \\
\text { Interval }\end{array}$ & $\begin{array}{c}\text { p- } \\
\text { value }\end{array}$ \\
\hline $\begin{array}{c}\text { Gender } \\
\text { Male }\end{array}$ & 1.10 & 0.83 & 1.44 & $\mathbf{0 . 5 2}$ & & \\
\\
\hline
\end{tabular}




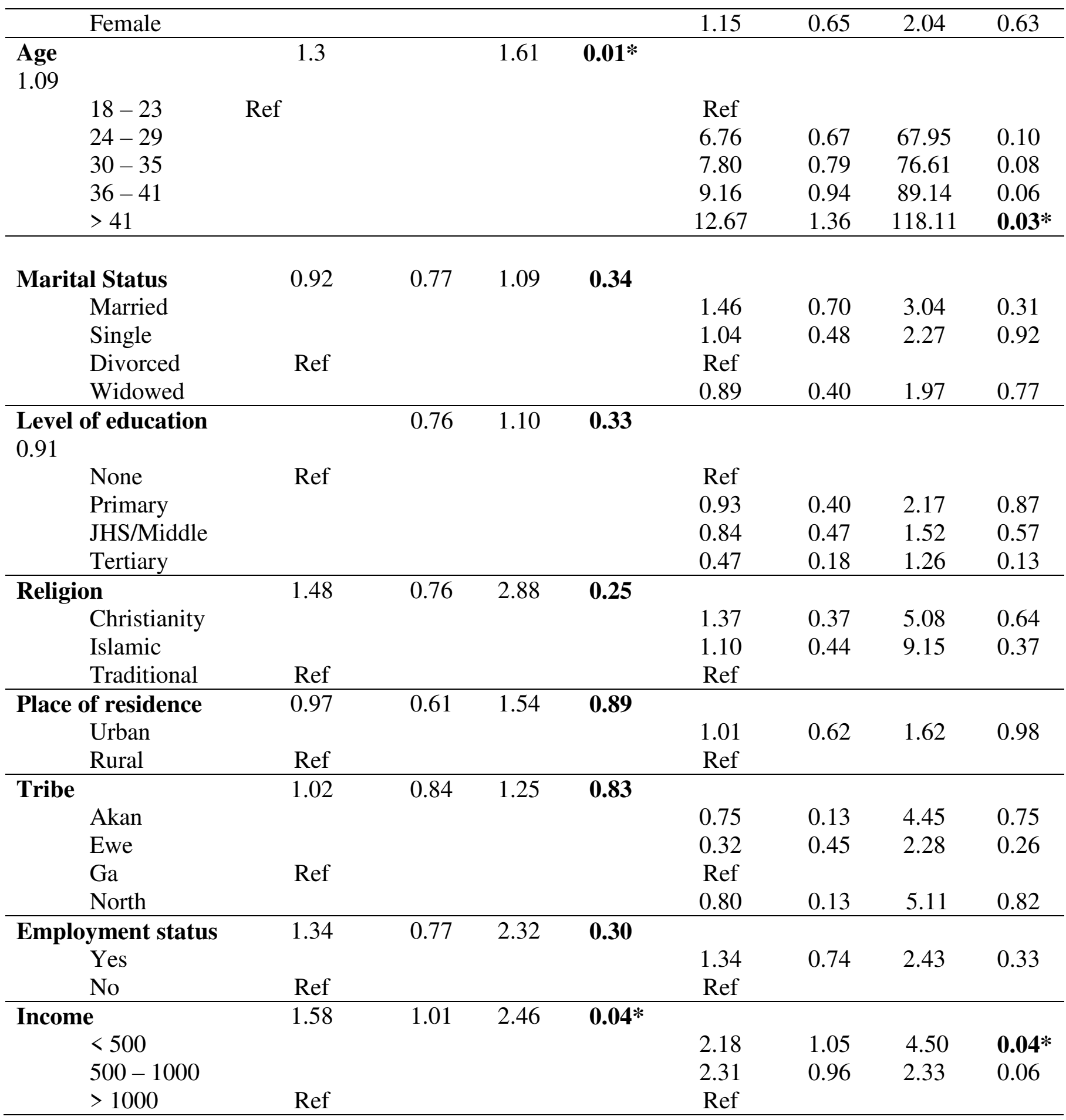

$206 * \mathrm{p}<0.05$; OR significant at 95\% CI; OR (95\% CI), unadjusted odds ratio from simple logistic

207 regression with accompanying 95\% confidence interval; aOR adjusted odds ratio determined using 208 multiple regression.

209 


\section{Discussion}

213 In this current study, we investigated the association between socio-demographic factors and 214 medication adherence among PLHIV in Kumasi Metropolis, Ghana. The study found that 215 medication adherence among PLHIV was 69.05\%. The level of medication adherence found in 216 this study is however higher than that of previous studies conducted in Volta region of Ghana ${ }^{30}$,

217 Upper West region of Ghana ${ }^{29}$, Western region of Ghana ${ }^{5}$ that found $51.4 \%, 62.2 \%$, and $67 \%$ 218 respectively. Also, previous studies conducted in Central region of Ghana ${ }^{28}$ and Eastern region of $219 \mathrm{Ghana}^{31}$ recorded higher rate of medication adherence to be $73 \%$ and $75 \%$ respectively. 220 Medication adherence rates in sub-Saharan Africa are quite inconstant and often pathetic and a 221 large number of patients are likely to progress to the AIDS stage when adherence is suboptimal ${ }^{33}$ 222

223 Understanding the socio-demographic factors of medication adherence among PLHIV could help 224 in the successful implementation of medication adherence intervention programmes ${ }^{28}$. The study 225 showed that age and monthly disposable income were significantly associated with medication 226 adherence among PLHIV. Specifically, PLHIV aged above 41 years were found to be more likely 227 to adhere to medication in this study. This finding is consistent with previous studies in Nigeria ${ }^{34,35}$ 228 and India ${ }^{16}$. Glass et al. ${ }^{35}$ and Falang, Akubaba and Jimam ${ }^{34}$ demonstrated an association between 229 medication adherence and improved outcomes increasing with age. The plausible reason for this 230 finding could be due to the fact that older people are more likely to have prior experience taking 231 medication for age-related diseases and the associated lifestyle adjustments required are often less 232 burdensome for older people ${ }^{16,36}$. 
233 The study also found that PLHIV who earned GHC500 as their monthly disposable income were

234 more likely to adhere to medication to those who earn GHC1000. The finding disagrees with the

235 finding of previous study in China ${ }^{26}$. Yu et al. ${ }^{26}$ demonstrated that PLHIV with high monthly

236 income adhere to their medication as they may have the financial capacity to afford any cost related

237 to their health. PLHIV with high monthly income may be more likely to be employed and they

238 spend much time at work influencing negatively with the consistent use of medication. However,

239 the plausible reason for this study finding could be that PLHIV with low monthly income may not

240 be actively employed and they may be extra careful about their health and in so doing, they will

241 do their best to adhere to medication as prescribed by healthcare providers to prolong their lives.

\section{Strengths and limitations}

243 It is important to explain the findings of the present study in respect to certain strengths and

244 limitations of the study. The main strength of the study is its use of first-hand information from

245 PLHIV in Ghana, which enables us to generalize the findings of the study to all PLHIV in Ghana.

246 The methodology and data collection technique for the survey featured standard data collection

247 methods, including the use of experienced researchers which resulted in a high response rate.

248 Moreover, in the study, we used advanced statistical tools for the analysis. This ensured a vigorous

249 analysis of the data. These strengths do not make the study immune to limitations. It must be

250 acknowledged that the cross-sectional study design adopted prevents us from drawing causal

251 relations between the variables studied. The study was also carried out in one hospital, however

252 this is the regional hospital where most of the PLHIV access healthcare. This will one way or the

253 other affect the generalization of the study in the country. The outcome variable was also measured

254 with a single item. 
257 The study has revealed that about (69) sixty-nine out of every (100) hundred PLHIV accessing 258 healthcare at Kumasi South Hospital in Kumasi Metropolis in the Ashanti Region of Ghana 259 adhered to their medication. Socio-demographic factors associated with medication adherence 260 were age, and disposable income. In further maximizing the medication adherence rate among 261 PLHIV in Ghana, policy makers such as Ghana AIDS Commission, Ministry of Health, Ghana 262 Health Service, and National AIDS Control Programme should consider factors such as socio263 demographic factors when designing and implementing programmes on medication adherence 264 among PLHIV. There is the need to conduct a qualitative study to gain deeper understanding of 265 how the identified factors affect medication adherence among PLHIV.

\section{List of abbreviations}

267 AIDS

268 ART

269 HIV

$270 \quad$ NACP

271 PLHIV

272 STI

273 UNAIDS

$274 \quad$ VCT
Acquired Immune Deficiency Syndrome

Antiretroviral Therapy

Human Immunodeficiency Virus

National AIDS Control Programme

People Living with HIV

Sexually Transmitted Disease

United Nations Joint Programme on HIV/AIDS

Voluntary Counselling and Testing for HIV 
1. UNAIDS. Ghana HIV and AIDS estimates. 2019. Available at: http://www/.unaids.org/en/regionscountries/countries/ghana. https://www.unaid.org/en/dataanalysis/datatods/aidsinfo.

3. UNAIDS. UNAIDS data 2017. Geneva, Switzerland. 2017. preventing HIV infection: recommendation for a public health approach: WHO, Geneva, Switzerland. 2016. 
5. Boakye, D. S. Adherence to antiretroviral therapy and its impact on clinical and immunologic outcomes. Ghana. 2015.

6. Abingyoure, A. B. Dietary intake patterns and adequacy of HIV-infected adults seeking clinical care in Accra, Ghana. University of Ghana. 2013. Available at: https://ugspace.edu.gh.

7. Ghana Statistical Service (GSS), Ghana Health Service (GHS), ICF Macro. Ghana 300 Demographic and Health Survey 2014 GSS, GHS, and ICF Macro, Accra, Ghana. 2015.

8. National AIDS Control Programme. Guidelines for antiretroviral therapy in Ghana. Accra, Ghana. 2016.

9. UNAIDS. Global HIV/AIDS Statistics- 2020 fact sheet. 2020.

10. Alakija, K. S., Fadeji, A., Ogunmodede, J. A. \& Desalu, O. Factors influencing adherence to antiretroviral medication in Ilorin, Nigeria. J Int Assoc Physicians AIDS Care 2010, $9(3), 191-5$

11. Carter, M. Information series for HIV-positive people HIV \& Children. Lithosphere. 2nd ed. London 2005, 1-36.

12. UNAIDS. Report on the global AIDS epidemic 2004. Available at: https://www.unaids.org/bangkok2004/CAR.

13. Ankrah, N.A. D., Koster, S. E., Mantel-Teeuwisse, K. A., Arhinful, K. D., Agyepong, A. I. \& Lartey, M. Facilitators and barriers to antiretroviral therapy adherence among adolescents in Ghana. Patient Preference and Adherence 2016, 10,329-337.

14. Chi, B. H., Cantrell, R. A., Zulu, I., Mulenga, L.B., Levy, J.W., Tambatamba, B.C. \& Stringer, J.S.A. Adherence to first-line antiretroviral therapy affects non-virologic 
outcomes among patients on treatment for more than 12 months in Lusaka, Zambia: Journal 2009, 746-756.

15. UNAIDS. Access to antiretroviral therapy in Africa: Status report on progress towards the 2015 targets. 2015.

16. Cauldbeck, M., O’Connor, C., O’Connor, M., Saunders, J., Rao, B. \& Mallesh, V. G. Adherence to antiretroviral therapy among HIV patients in Bangalore, India. AIDS Res Ther 2009, 6, 7. 95(3361).

17. Bezabhe, W. M., Chalmers, L., Bereznicki, L. R. \& Peterson, G. M. Adherence to antiretroviral therapy and viologic failure: a meta-analysis. Medicine (Baltimore) 2016,

18. Hass, A. D. Adherence to antiretroviral therapy during and after pregnancy: cohort study on women receiving care in Malawi's option B+ program. Clin Infect Dis 2016, 63, 12271235.

19. Turner, B. J. Adherence to antiretroviral therapy by human immunodeficiency virusinfected patients. J Infect Dis 2002, 185,143-151.

20. Paterson, D. L., Swindells, S., Mohr, J., Brester, M., Vergis, E. N. A, Squier, C., Wagener, M. \& Singh, N. Adherence to Protease Inhibitor Therapy and Outcomes in Patients with HIV Infection. Annals of Internal Medicine 2000, 133, 21-30.

21. Dzansi G, Tornu E, Chipps J. Promoters and inhibitors of treatment adherence among HIV/AIDS patients receiving antiretroviral therapy in Ghana: Narratives from an underserved population. PLoS ONE 2020, 15(3), e0230159. https://doi.org/10.1371/journal.pone.0230159. 
22. Harrigan, P.R. Predictors of HIV drug-resistance mutations in a large antiretroviral-naïvecohort initiating triple antiretroviral therapy. J Infect Dis 2005, 191,339-347.

23. Hogg, R.S., Heath, K., Bangsberg, D., Yip, B., Press, N., O’Shaughnessy, MV. \& Montaner, JS. Intermittent use of triple-combination therapy is predictive of mortality at baseline and after 1 year of follow-up. AIDS 2002, 16, 1051-1058.

24. Bijker R, Jiamsakul A, Kityo C, Kiertiburanakul S, Siwale M, Phanuphak P, Akanmu S, Chauwarith R, Wit FW, Sim BLH, Boender TS, Ditangco R, Rinker De Wit TF, Sohn AH,

Hamers R. Adherence to antiretroviral therapy for HIV in sub-Saharan Africa and Asia: a comparative analysis of two regional cohorts. Journal of the International AIDS Society, 2017, 20(1), 21218.

25. Ayalu A. Reda \& Sibhatu Biadgilign. Determinants of adherence to antiretroviral therapy among HIV-infected patients in Africa. AIDS Research and Treatment, 2012, 2012(574656), 8 .

26. Yu, Y., Dan, L., Xi, C., Zhulin, H., Min, W. \& Shuiyuan, X. Medication adherence to ART among newly treated people living with HIV. BMC Public Health 2018, 18,825.

27. Madiba S \& Josiah U. Perceived stigma and fear of unintended disclosure are barriers in medication adherence in adolescents with perinatal HIV in Botswana: A qualitative study. Biomed Res Int,2019,9623159.

28. Prah, J., Anna, H., Mohammed, A., Obed, L., Yvonne N. \& Dorcas O. Y. Factors affecting adherence to ART among HIV/AIDS patients in Cape Coast metropolis, Ghana. Journal of HIV/AIDS 2018, 4(1). 
29. Obirikorang C, Sellah P .K, Abledu J. K, Fofie C.O. Predictors of adherence to antiretroviral therapy among HIV/AIDS patients in the upper west region of Ghana. ISRN AIDS 2013.

30. Okotah AN, Korbuvi J. Adherence to antiretroviral therapy among adult HIV positive patients in Volta Regional Hospital, Ghana. Value Health 2014,17, A329.

31. Baah-Danso M. Factors influencing adherence to antiretroviral therapy among people living with HIV and AIDS in Koforidua Regional Hospital. 2017. http://ugspace.ug.edu.gh/handle/123456789/23806

32. Setia, MS. Methodology series module 3: Cross-sectional studies. Indian J Dermatol 2016, 61(3), 261-4.

33. Gill, C. J., Hamer, D. H., Simon, J. L., Thea, M., Sabin, L. L. No room for complacency about adherence to antiretroviral therapy in sub-Saharan Africa. AIDS 2005, 19 (12), 12431249.

34. Falang KD., Akubaba P., \& Jimam NS. . Patient factors impacting antiretroviral drug adherence in a Nigerian tertiary hospital. J Pharmacol Pharmacother 2012, 3(2), 138-142.

35. Tracy R. Glass, Pietro L. Vernazza, Enos Bernasconi \& Manuel Battegay. Correlates of self-reported nonadherence to antiretroviral therapy in HIV-infected patients. The Swiss HIV Cohort Study. J Acquir Immune Defic Syndr, 2006, 41(3).

36. Adefolalu, A.O. \& Nkosi, I. The Complex Nature of Adherence in the Management of HIV/AIDS as a Chronic Medical Condition. Diseases 2013, 1, 18-35. 


\section{Declaration}

\section{Ethics approval and informed consent to participate}

383 Ethical clearance was first sought from the Committee on Human Research, Publications and

384 Ethics (CHRPE), Kwame Nkrumah University of Science and Technology as well as permission 385 was sought from the management of the regional hospital. All participants and subjects involved 386 were given an informed consent form after a verbal and written explanation of the methods, and 387 risks involved using an information sheet. Those who agreed to be part of this study were made 388 either to sign or thumbprint an informed consent form. Participants with none or primary 389 education, an informed consent was sought from their legal guardians of the participants. However, 390 all methods that was carried out in the study were in line with the relevant guidelines and 391 regulations of human experiment study.

\section{Consent for publication}

393 All participants were informed of the publication of the results of the study in peer-reviewed 394 journal.

396 Availability of data and materials

397 The datasets generated during the current study are not publicly available due to the confidentiality 398 of the participants' information but are available from the corresponding author on reasonable 399 request. 


\section{Authors' contribution}

402

403 CA, KAM, BOA, AS, AYM and AWT contributed to the conceptualization, the design of the 404 study. CA, AWT, BOA, AS, and AYM contributed to the acquisition of the data, data analysis, 405 and the interpretation of the data. CA and KAM drafted the manuscript and made all revisions.

406 KAM, BOA and AS provided critical intellectual input in the manuscript drafting and revising 407 process. All authors approved the final manuscript and take public responsibility for the content 408 of the present work. All authors agreed to be accountable for all aspects of the work in ensuring 409 that questions related to the accuracy or integrity of any part of the work are appropriately 410 investigated and resolved.

411

\section{Acknowledgement}

413

414 We are grateful to all participants who generously contributed their time for this study. We 415 would like to thank the entire staffs of the HIV unit of Kumasi South Hospital who helped 416 facilitate the study. Also, we want to express our sincere gratitude to Abraham Awuah, 417 Ebenezer Frimpong, and Serwaa Akoto Arthur, who played the key role in data collection, 418 and data management.

\section{$420 \quad$ Funding}

421

422 The study did not receive any funding.

423 


\section{Competing interests}

425

426 The authors declare that they have no competing interests.

427 
Figures

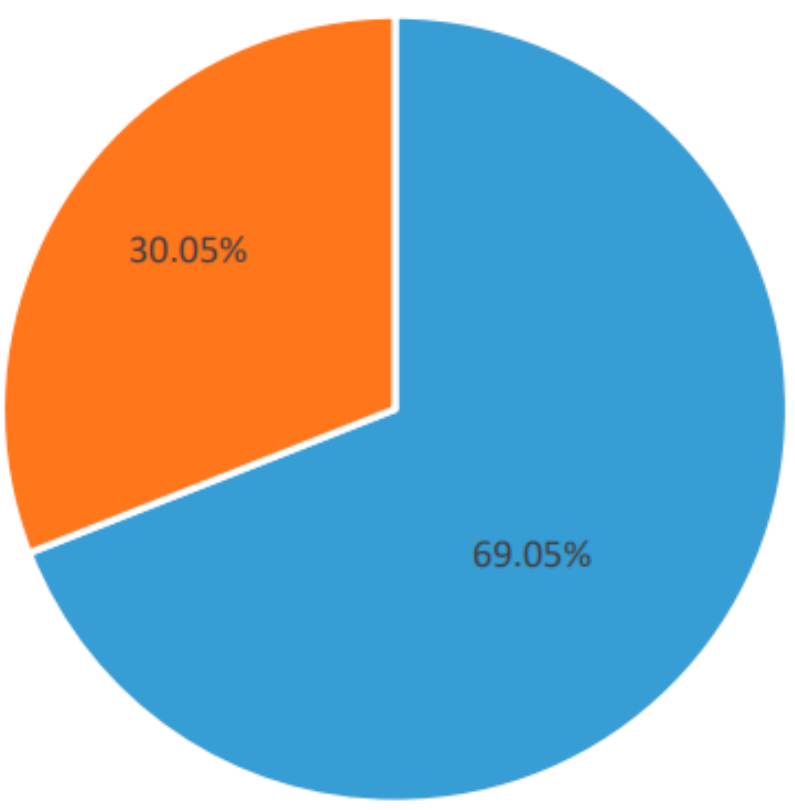

- Yes = No : "

\section{Figure 1}

Medication adherence among PLHIV 